\title{
Beta-Amyloid Downregulates MDR1-P-Glycoprotein (Abcb1) Expression at the Blood-Brain Barrier in Mice
}

\author{
Anja Brenn, ${ }^{1}$ Markus Grube, ${ }^{2}$ Michele Peters, ${ }^{1}$ Andrea Fischer, ${ }^{1}$ Gabriele Jedlitschky, ${ }^{2}$ \\ Heyo K. Kroemer, ${ }^{2}$ Rolf W. Warzok, ${ }^{1}$ and Silke Vogelgesang ${ }^{1}$ \\ ${ }^{1}$ Department of Neuropathology, Institute of Pathology, University of Greifswald, 17487 Greifswald, Germany
${ }^{2}$ Department of Pharmacology, Research Center of Pharmacology and Experimental Therapeutics, University of Greifswald,
17487 Greifswald, Germany
}

Correspondence should be addressed to Silke Vogelgesang, silke.vogelgesang@uni-greifswald.de

Received 26 January 2011; Accepted 4 April 2011

Academic Editor: Brian J. Balin

Copyright (c) 2011 Anja Brenn et al. This is an open access article distributed under the Creative Commons Attribution License, which permits unrestricted use, distribution, and reproduction in any medium, provided the original work is properly cited.

\begin{abstract}
Neurovascular dysfunction is an important component of Alzheimer's disease, leading to reduced clearance across the blood-brain barrier and accumulation of neurotoxic $\beta$-amyloid $(\mathrm{A} \beta)$ peptides in the brain. It has been shown that the ABC transport protein $\mathrm{P}$ glycoprotein (P-gp, ABCB1) is involved in the export of $A \beta$ from the brain into the blood. To determine whether $A \beta$ influences the expression of key $\mathrm{A} \beta$ transporters, we studied the effects of 1-day subcutaneous $\mathrm{A} \beta 1-40$ and $\mathrm{A} \beta 1-42$ administration via Alzet miniosmotic pumps on P-gp, BCRP, LRP1, and RAGE expression in the brain of 90-day-old male FVB mice. Our results demonstrate significantly reduced P-gp, LRP1, and RAGE mRNA expression in mice treated with A $\beta 1-42$ compared to controls, while BCRP expression was not affected. The expression of the four proteins was unchanged in mice treated with A $\beta 1-40$ or reverse-sequence peptides. These findings indicate that, in addition to the age-related decrease of P-gp expression, $A \beta 1-42$ itself downregulates the expression of P-gp and other $\mathrm{A} \beta$-transporters, which could exacerbate the intracerebral accumulation of $\mathrm{A} \beta$ and thereby accelerate neurodegeneration in Alzheimer's disease and cerebral $\beta$-amyloid angiopathy.
\end{abstract}

\section{Introduction}

Burgeoning evidence implicates cerebrovascular dysfunction in the cognitive decline and neurodegeneration that characterize Alzheimer's disease (AD) $[1,2]$. Impaired clearance of $\beta$-amyloid $(\mathrm{A} \beta)$ across the blood-brain barrier (BBB) and the senescence of the cerebrovascular system are thought to initiate processes that contribute to neurodegeneration $[1,3]$. The transport of $\mathrm{A} \beta$ across the $\mathrm{BBB}$ comprises a two-step process involving transport through the abluminal (brain side) and then through the luminal (blood side) plasma membranes of the endothelial cells. The lowdensity lipoprotein receptor-related protein-1 (LRP1) mediates the incorporation of brain-derived $\mathrm{A} \beta$ peptides into the endothelial cells at the abluminal membrane $[4,5]$. On the other hand, the receptor for advanced glycation end products (RAGE) is considered to be a major influx transporter of peripherally derived (blood-borne) $\mathrm{A} \beta$ into the endothelial cells of the cerebral vasculature $[6,7]$. The $\mathrm{ABC}$ transporter
P-glycoprotein (P-gp, ABCB1) is highly expressed at the luminal side of the endothelial cells that form the BBB, and may play a key role in the transport of $\mathrm{A} \beta$ peptides (either brain or blood derived) into the blood [8]. In vitro and in vivo experiments have shown that $\mathrm{P}$-gp is an active transport protein for $A \beta 1-40$ and $A \beta 1-42$ [9-14]. These observations suggest that diminished $\mathrm{P}$-gp expression due to increasing age, genetic, or environmental factors may lead to impaired $\mathrm{A} \beta$ clearance, followed by the accelerated accumulation of intracerebral $\mathrm{A} \beta$ and eventually the development of $\mathrm{AD}$.

An autopsy study of nondemented elderly humans found that vessels with $\mathrm{A} \beta$ accumulation within their walls (cerebral amyloid angiopathy, CAA) showed little or no endothelial P-gp expression whereas unaffected capillaries had high Pgp expression, leading to the hypothesis that $A \beta$ leads to a downregulation of P-gp expression whereas P-gp might be upregulated in the endothelium of capillaries lacking $\mathrm{A} \beta$ accumulation in an attempt to compensate for the loss of P-gp in amyloid-bearing vessels [11]. Thus, the aim of 
the present study is to investigate the effect of $\mathrm{A} \beta$ administration on the expression of P-gp and other $A \beta$ transporters in endothelial cells of the cerebral vasculature.

\section{Material and Methods}

2.1. Laboratory Animals. 90 day-old male FVB wildtype mice (purchased from Taconic, Hudson, NY, USA) weighing approximately $25 \mathrm{~g}$ were used. Animal care and experimental conditions were conducted in compliance with protocols approved by the local Animal Care and Use Committee.

2.2. Preparation and Subcutaneous Implantation of ALZET Mini-Osmotic Pumps. 10-12 animals per group were used for the systemic administration of $A \beta 1-40$ (DAEFRHDSGYEVHHQKLVFFAEDVGSNKGAIIGLMVGGVV), A $\beta 1-42$ (DAEFRHDSGYEVHHQKLVFFAEDVGSNKGAIIGLMVGGVVIA), or reverse A $\beta 40-1$ (VVGGVMLGIIAGKNSGVDEAFFVLKQHHVEYGSDHRFEAD) or reverse A $\beta 42-1$ (AIVVGGVMLGIIAGKNSGVDEAFFVLKQHHVEYGSDHRFEAD). All peptides were purchased from AnaSpec Inc. (Fremont, CA, USA).

$1 \mathrm{mg}$ of each peptide was dissolved in $4 \mu \mathrm{L}$ DMSO and mixed with $2 \mathrm{~mL}$ isotonic $\mathrm{NaCl}$ solution, yielding a final $\mathrm{A} \beta$ concentration of $0.5 \mu \mathrm{g} / \mu \mathrm{L}$. $200 \mu \mathrm{L}$ ( $=100 \mu \mathrm{g}$ peptide) of this solution were used to fill the Alzet mini-osmotic pumps. $200 \mu \mathrm{L}$ of isotonic $\mathrm{NaCl}$ solution served as vehicle control.

ALZET mini-osmotic pumps (model 2001D; DURECT Corporation, Cupertino, USA) were implanted subcutaneously using a midscapular incision. Pumps delivered synthetic, human-type sequence $A \beta 1-40, A \beta 1-42$, reverse $A \beta 40$ 1 , A $\beta 42-1$ peptide, or isotonic $\mathrm{NaCl}$ solution, respectively. After a 2-hour start-up transient, the pumps infuse at a constant pumping rate of $8 \mu \mathrm{Lh}^{-1}$.

After $26 \mathrm{~h}$ mice were sacrificed by cervical dislocation and the brains were immediately removed. One hemisphere was shock-frozen in liquid nitrogen and stored at $-80^{\circ} \mathrm{C}$ until use. The other hemisphere was fixed with neutral-buffered $4.5 \%$ formalin and was embedded in paraffin.

2.3. Real-Time PCR Analyses. For real-time PCR analysis, RNA was isolated from deep-frozen brain tissue using the RNeasy Mini kit form Qiagen according to the manufacturer's instructions (Qiagen, Hilden, Germany). Reverse transcription of total-RNA was performed by the TaqMan reverse transcription kit using random hexamer primers (Applied Biosystems, Darmstadt, Germany). Quantitation of RNA (cDNA) levels for Abcb1a, Abcg2 (Mm00496364_m1), LRP1 (Mm00464608_m1), as well as RAGE (Mm00545815_ $\mathrm{m} 1$ ) and 18SrRNA (part \# 4319413E) for normalization was performed by real-time PCR on a 7900HT TaqMan system (Applied Biosystems) using predeveloped TaqMan assays (Assays on Demand, Applied Biosystems). All PCR reactions were performed in $10 \mu \mathrm{L}$ reactions using a PCR master mix $(2 \mathrm{x}$ concentrated) containing $45 \mathrm{mmol} / \mathrm{L}$ Tris- $\mathrm{HCl}$ (pH 8.4), $115 \mathrm{mmol} / \mathrm{L} \mathrm{KCl}, 7 \mathrm{mmol} / \mathrm{L} \mathrm{MgCl}_{2}, 460-\mu \mathrm{mol} / \mathrm{L}$ dNTPs, 9\% glycerol, 2.3\% ROX reference dye (Invitrogen, Paisley, Scotland) and $0.035 \mathrm{U} / \mathrm{mL}$ Platinum Taq DNA polymerase (Invitrogen). Thermal cycler conditions were as follows: $\left(50^{\circ} \mathrm{C}, 2 \mathrm{~min}\right.$; $95^{\circ} \mathrm{C}, 10 \mathrm{~min}$ followed by 40 cycles of $95^{\circ} \mathrm{C}, 15 \mathrm{~s}$ and $\left.60^{\circ} \mathrm{C}, 1 \mathrm{~min}\right)$.

Expression analysis was performed by the comparative $\Delta \Delta \mathrm{Ct}$-method using the expression of 18SrRNA as reference gene.

2.4. Immunohistochemistry. For immunohistochemistry, brain tissues were fixed in neutral-buffered, isotonic $4.5 \%$ formalin and embedded in paraffin. $1 \mu \mathrm{m}$-thick tissue sections were cut, mounted on slides and dried overnight at $60^{\circ} \mathrm{C}$. For staining, the biotin-streptavidin immunoperoxidase method with polymer detection system-HRP was used. Automated immunohistochemical staining was performed using the BOND-MAX (Leica) staining systems using pre-diluted antibodies to murine P-gp (clone C219, dilution $1: 25, \mathrm{pH}$ 9.0, Enzo Life Sciences) and BCRP (clone BxP53, dilution 1:50, pH 9.0, Enzo Life Sciences).

Negative controls for each treatment were processed without primary antibody.

2.5. Image Acquisition and Analysis. Digital images were captured using the Zeiss Mirax Scan Desk slide scanner (Carl Zeiss MicroImaging GmbH, Göttingen, Germany; PlanApochromat 20x/0.8, pixel resolution: $0.37 \mu \mathrm{m})$. To quantitate P-gp expression, image analysis algorithms were developed using ImageJ (version 1.43 q, Research Services Branch, National Institute of Mental Health/National Institutes of Health, Bethesda, MD, USA; http://rsb.info.nih.gov/ij/), which allowed the identification and analysis of immunolabeled cerebral capillaries in digital images. The amount of P-gp-specific labelling in each animal was determined in ten high-power fields (x40) of the brain cortex, the staining intensity for cortical P-gp of a single animal was the mean of all measurements.

2.6. Statistical Analysis. Statistical analysis was performed using Microsoft Excel and GraphPad Prism 5.01 (GraphPad, San Diego, USA) software using the $\Delta \mathrm{Ct}$ expression values. The statistical tests employed are indicated in the respective sections/figure legends. If the data are represented as boxplots, the whiskers indicate the 10th and 90th percentiles.

\section{Results}

First, mRNA expression for P-gp (Abcbla), BCRP (Abcg2), LRP1, and RAGE was measured by real-time PCR in mice treated with $\mathrm{A} \beta 1-42$, vehicle control, or the reverse protein (A $\beta 42-1)$ for $24 \mathrm{~h}$ using subcutaneously transplanted ALZET pumps. Transporter expression was detected in all samples for Abcb1a and Abcb2 while analysis of LRP1, and RAGE failed in one A $\beta 1-42$-treated mouse. Significant changes in the expression of Abcb1a, LRP1 and RAGE were detected in mice given $A \beta 1-42$. While transporter expression was not significantly altered between the control perfusion group and the mice treated with equal amounts of the reverse $\mathrm{A} \beta$ protein, animals treated with $\mathrm{A} \beta 1-42$ had significantly reduced Abcbla levels in brain (reduced by $63 \pm 24 \%$ [mean $\pm \mathrm{SD}]$ ) compared to mice given the vehicle control, and 


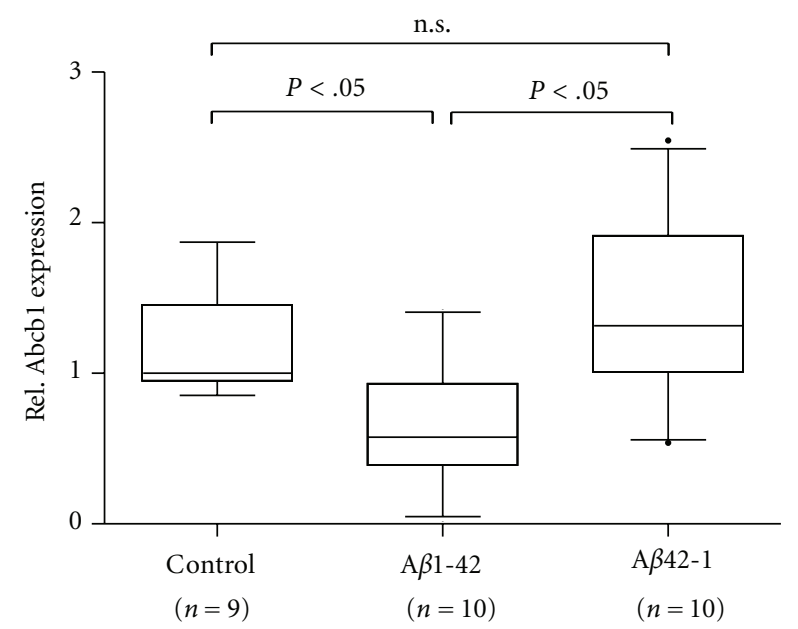

(a)



(c)

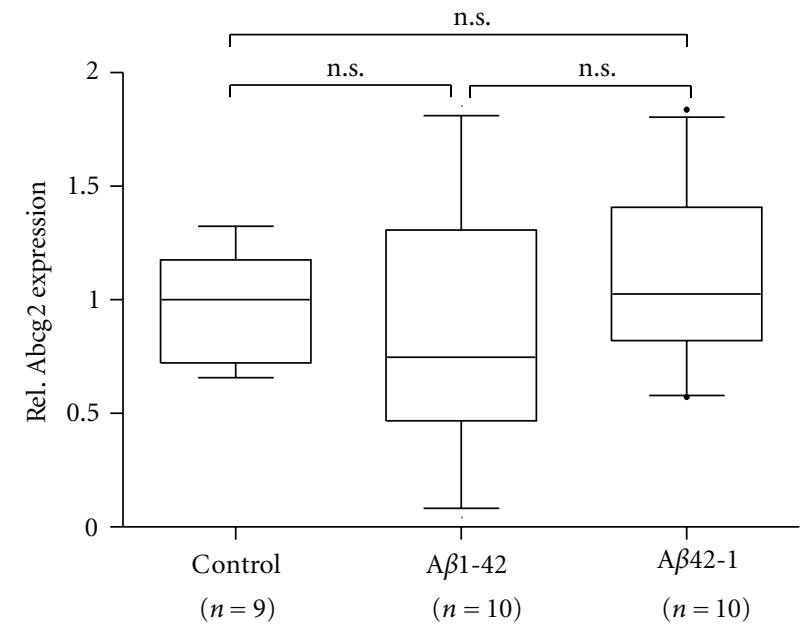

(b)

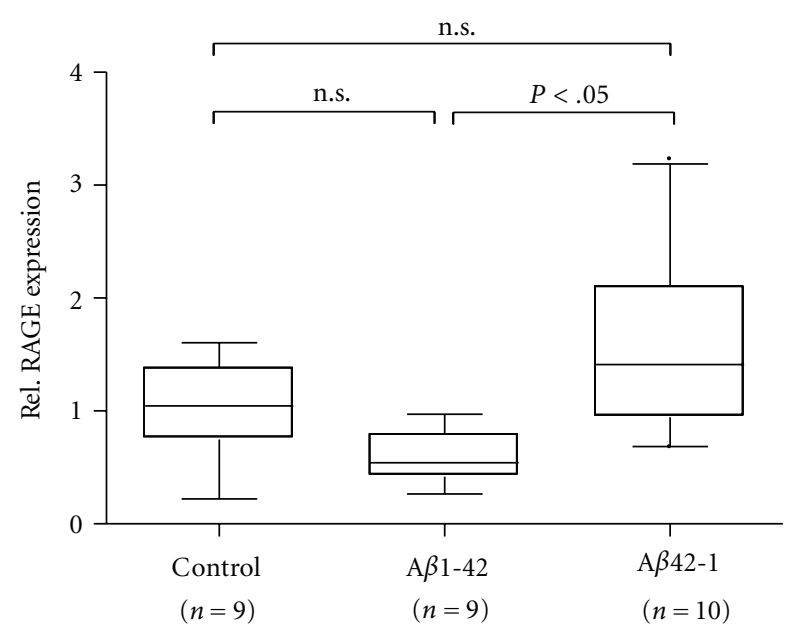

(d)

Figure 1: mRNA expression of Abcbla (a), Abcg2 (b), LRP1 (c), and RAGE (d) in murine brain. Mice were treated with $\beta$-amyloid 1-42 (A $\beta 1-42)$, reverse $\beta$-amyloid 42-1 (A $\beta 42-1)$ and vehicle control (control) using ALZET pumps for $24 \mathrm{~h}(4 \mu \mathrm{g} / \mathrm{h})$. mRNA expression of each transporter was normalized to $18 \mathrm{~S}$ rRNA expression and values are depicted in relation to the median expression in vehicle perfused mice. Statistical analysis was performed by one-way ANOVA followed by Newmann-Keuls Multiple Comparison test.

by $54 \pm 30 \%$ compared to mice given the reverse-sequence protein), LRP1 levels (reduced by $57 \pm 17 \%$ ) compared to vehicle controls and by $60 \pm 17 \%$ compared to the reverse protein controls); and RAGE levels (reduced by $65 \pm 15 \%$ compared to the reverse protein controls, no significant difference relative to vehicle controls Figures 1(a), 1(c), and 1(d)). In contrast, expression of Abcg2 remained unchanged in these samples (Figure 1(b)).

In a second experiment, mice were treated with $\mathrm{A} \beta 1-40$ in a similar manner. Here, no significant changes were detected in any of the four proteins; however, the expression of RAGE tended to be lower compared to the vehicle control samples (Figures 2(a)-2(d)).

At the protein level, P-gp and BCRP were detectable in endothelial cells of brain vessels in all animals using immunohistochemistry (Figures 3(a) and 3(b)). However, quantitatively no changes of P-gp or BCRP could be detected after administration of $A \beta 1-42$ or $A \beta 1-40$ in comparison to the reverse $\mathrm{A} \beta$ peptides or vehicle control, respectively (data not shown).

\section{Discussion}

There is growing evidence that an alteration of the transport of $\mathrm{A} \beta$ peptides across the $\mathrm{BBB}$ plays a crucial role in the pathogenesis of $\mathrm{AD}$ and CAA. In addition to other transport proteins such as LRP1 and RAGE, the multidrug resistance transport protein $\mathrm{P}$-gp is known to eliminate $\mathrm{A} \beta 1-40$ and $\mathrm{A} \beta 1-42$ from the brain [12-14]. In nondemented elderly humans, $A \beta$ deposition is inversely correlated with brain capillary P-gp expression [10]. Interestingly, investigations of the correlation between CAA and P-gp expression indicate a loss of $\mathrm{P}$-gp in vessels with abundant cerebrovascular $A \beta$ accumulation. In this study, CAA was 


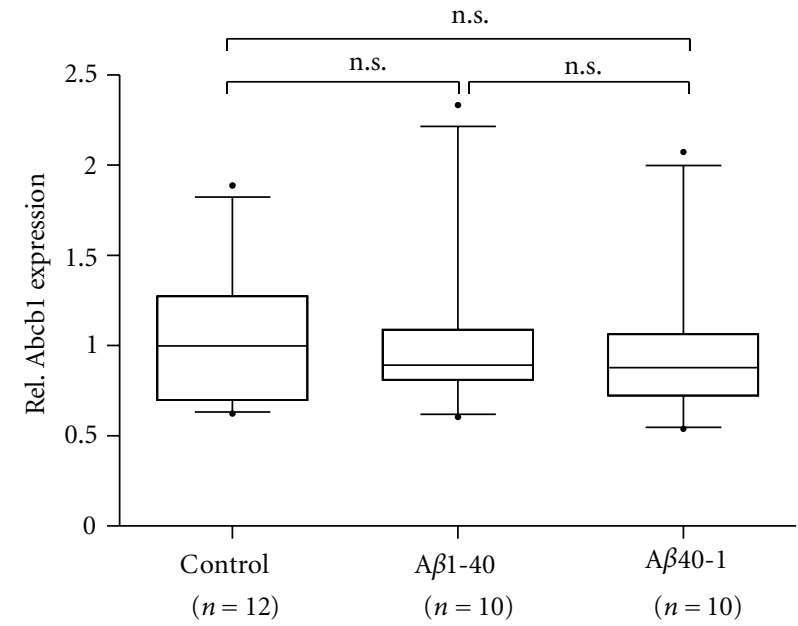

(a)



(c)



(b)

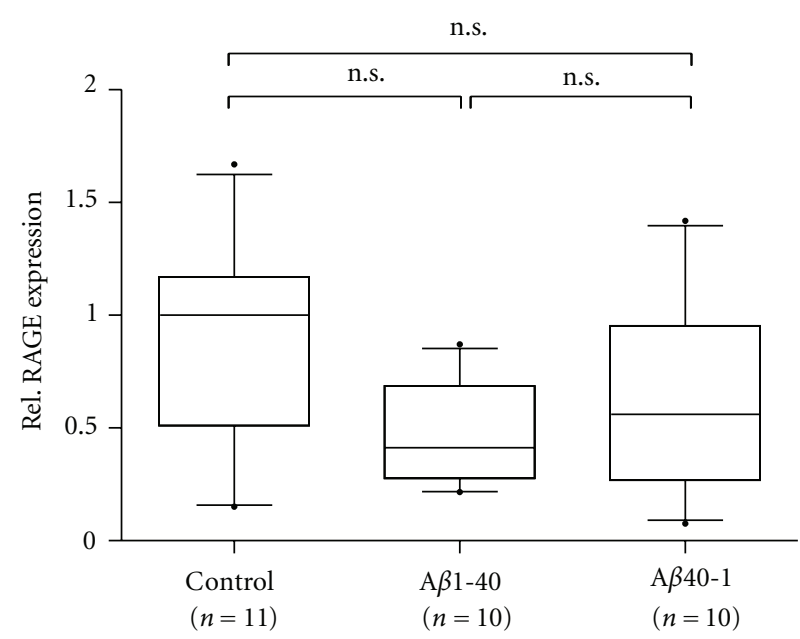

(d)

Figure 2: mRNA expression of Abcb1a (a), Abcg2 (b), LRP1 (c) and RAGE (d) in murine brain. Mice were treated with $\beta$-amyloid 1-40 (A $\beta 1-40)$, reverse-sequence $\beta$-amyloid 40-1 (A $\beta 40-1)$ and vehicle control (control) using ALZET pumps for $24 \mathrm{~h}(4 \mu \mathrm{g} / \mathrm{h})$. mRNA expression of each transporter was normalized to $18 \mathrm{~S}$ rRNA expression, and values are depicted in relation to the median expression in vehicle-perfused mice. Statistical analysis was performed by one-way ANOVA followed by Newmann-Keuls Multiple Comparison test.

primarily found in small arteries, but in the advanced stages of CAA, the capillaries also were affected [11], leading to the question of how $A \beta$ itself affects P-gp expression in the endothelial cells that are a key component of the BBB.

The present study found that peripherally administered A $\beta 1-42$ leads to a decrease of P-gp expression in vivo in mouse brains at the mRNA level. This finding is in concordance with the results of Hartz et al., who reported that P-gp expression and transport activity are compromised in brain capillaries isolated from hAPP transgenic mice that exhibit accumulation of human-type $\mathrm{A} \beta$ within the brain [14]. Thus, it can be hypothesized that the compromising effect of $\mathrm{A} \beta$ on P-gp expression leads to a further increase of $A \beta$ accumulation, thus initiating a vicious circle that exacerbates the progression of the disease.
LRP1 is localized at the brain-side membrane of capillaries; as a receptor for $\mathrm{A} \beta$, LRP1 mediates the transport of the peptide from the brain into the endothelial cells. LRP1 expression was reported to be reduced during normal aging in animals and in $\mathrm{AD}$ patients associated with accumulation of $\mathrm{A} \beta 1-40$ and $\mathrm{A} \beta 1-42$ within the cerebral vessels $[4,15$, 16]. Our results revealed significantly reduced levels of LRP1 mRNA in mice treated with $A \beta 1-42$, confirming the lowering effect of $A \beta$ on LRP1 expression. However, 12-week-old hAPP mice revealed slightly increased LRP1 expression whereas RAGE was unchanged, suggesting the critical limiting step in $\mathrm{A} \beta$ brain clearance could be $\mathrm{P}$ gp-mediated $\mathrm{A} \beta$ transport across the luminal endothelial membrane into the blood [14].

RAGE is normally expressed at the luminal side of the endothelial cells, and mediates the transport of $A \beta 1-40$ and 


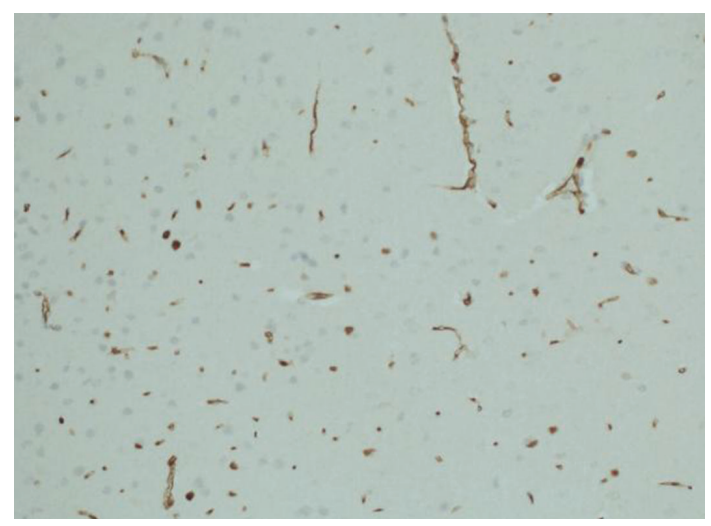

(a)

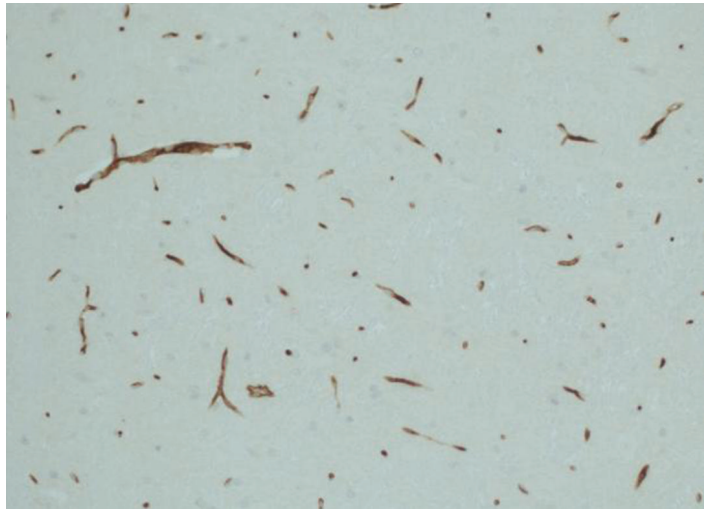

(b)

FIGURE 3: Immunohistochemical expression of P-gp (a) and BCRP (b) in endothelial cells of mice brain capillaries (original magnification $\times 200)$.

$\mathrm{A} \beta 1-42$ from blood into the endothelium [6]. In $\mathrm{AD}$ and $\mathrm{AD}$ models, cerebrovascular RAGE was shown to be increased [17]. Our results show that mRNA levels were significantly reduced in mice treated with $\mathrm{A} \beta 1-42$ in comparison to the reverse-sequence peptide. Relative to the vehicle control, RAGE mRNA expression showed a trend to be reduced by $\mathrm{A} \beta 1-42$, but did not reach statistical significance. However, our findings are in concordance with the observation that the expression of RAGE in Brown-Norway/Fischer rats decreases in early stages of $A \beta$ accumulation and increases with advanced age [18]. This suggests that an increase of RAGE expression plays a role in the later stages but not in the initiation of AD.

Our results show that $A \beta 1-42$, but not $A \beta 1-40$, inhibits P-gp, LRP1 and RAGE expression at the BBB. Under physiological conditions, the ratio of $A \beta 1-42$ to $A \beta 1-40$ in the brain is about $1: 10$ [19]. Thus, the amount of $A \beta 1-40$ in our pumps might have been too low to achieve sufficient effects on P-gp expression at the capillary endothelial cells. However, since the aggregative ability and the neurotoxicity of $A \beta 1-42$ are much greater than those of $A \beta 1-40, A \beta 1$ 42 plays a more important role in the pathogenesis of $\mathrm{AD}$ $[19,20]$. In this regard, $A \beta 1-42$ was reported to induce free radical-related oxidative stress and neurodegeneration in $\mathrm{AD}$ brains [21]. Interestingly, in contrast to $\mathrm{A} \beta 1-40$, the concentration of free $A \beta 1-42$ in cerebrospinal fluid is lower in patients with $\mathrm{AD}$, suggesting that $\mathrm{A} \beta 1-42$ might be preferentially incorporated into growing plaques [20].

In our study, the decrease of P-gp expression was observed at the mRNA level but not at the protein level using immunohistochemistry. This might be due to the short period during which $A \beta$ is present within the blood, leading to acute effects of $A \beta$ on transcription processes that were not reflected in changes of protein expression within this timeframe. Possibly, a longer treatment period is necessary to address this question.

Like P-gp, BCRP is localized at the luminal site of vascular endothelial cells and contributes to the integrity of the blood brain barrier (BBB), thus protecting the brain parenchyma from the damaging effects of xenobiotics [22]. P-gp and
BCRP share extensive similarities regarding their substrate specificity, and the list of substrates of BCRP has been steadily expanding since its discovery [23]. Using a human brain endothelial cell line (hCMEC/D3) A $\beta 1-40$ has been shown to be a substrate of BCRP [24]. Xiong et al. reported that $\mathrm{BCRP}$ mediates the transport of $\mathrm{A} \beta$ in $\mathrm{BCRP}$-overexpressing cell lines, and that $\mathrm{A} \beta$ accumulates in the brains of BCRPknockout mice. On the other hand, BCRP expression was increased in brain tissue of $\mathrm{AD}$ cases [25]. However, in the present study we found BCRP expression to be unchanged by circulating $A \beta$. This is in agreement with the findings on young hAPP mice, where no evidence was found for BCRPmediated $A \beta$ transport in brain capillaries [14]. Thus, it can be hypothesised that BCRP, like RAGE, might not be involved in the early stages of $\mathrm{AD}$, but rather may play a role in more advanced stages of the disease.

\section{Conclusions}

These findings lend further support for the involvement of the $\mathrm{ABC}$ transport protein P-gp in the transport of $\mathrm{A} \beta$ across the BBB. Specifically, circulating A $\beta$ itself lowers $\mathrm{P}$ $\mathrm{gp}$ expression at the $\mathrm{BBB}$, leading to a circulus vitiosus that triggers further $\mathrm{A} \beta$ accumulation. The activity of $\mathrm{P}$ gp is well known to be modulated pharmacologically by a range of commonly used drugs [26-28]. Thus, restoring Pgp function could be a novel therapeutic strategy to protect the brain from $\mathrm{A} \beta$ accumulation, and thus could be a tool to prevent and/or slow the progression of CNS disorders such as Alzheimer's disease.

\section{Acknowledgments}

The authors gratefully acknowledge helpful comments by Lary Walker (Emory University) and the excellent technical help of Cathrin Müller and Katrin Sokolowski, Department of Pathology, as well as of Tina Sonnenberger, Department of Pharmacology. The paper was supported by FP7-REGPOT20081-1 CSA Project ImpactG; Grant agreement no. 229750. 


\section{References}

[1] B. V. Zlokovic, "Neurovascular mechanisms of Alzheimer's neurodegeneration," Trends in Neurosciences, vol. 28, no. 4, pp. 202-208, 2005.

[2] C. Iadecola, "The overlap between neurodegenerative and vascular factors in the pathogenesis of dementia," Acta Neuropathologica, vol. 120, no. 3, pp. 287-296, 2010.

[3] R. Deane, R. D. Bell, A. Sagare, and B. V. Zlokovic, "Clearance of amyloid- $\beta$ peptide across the blood-brain barrier: implication for therapies in Alzheimer's disease," CNS and Neurological Disorders Drug Targets, vol. 8, no. 1, pp. 16-30, 2009.

[4] M. Shibata, S. Yamada, S. R. Kumar et al., "Clearance of Alzheimer's amyloid-ss(1-40) peptide from brain by LDL receptor-related protein-1 at the blood-brain barrier," Journal of Clinical Investigation, vol. 106, no. 12, pp. 1489-1499, 2000.

[5] R. Deane, A. Sagare, and B. V. Zlokovic, "The role of the cell surface LRP and soluble LRP in blood-brain barrier A $\beta$ clearance in Alzheimer's disease," Current Pharmaceutical Design, vol. 14, no. 16, pp. 1601-1605, 2008.

[6] R. Deane, Y. S. Du, R. K. Submamaryan et al., "RAGE mediates amyloid- $\beta$ peptide transport across the blood-brain barrier and accumulation in brain," Nature Medicine, vol. 9, no. 7, pp. 907-913, 2003.

[7] R. Deane, Z. Wu, and B. V. Zlokovic, "RAGE (yin) versus LRP (yang) balance regulates Alzheimer amyloid $\beta$-peptide clearance through transport across the blood-brain barrier," Stroke, vol. 35, no. 11, pp. 2628-2631, 2004.

[8] G. Lee and R. Bendayan, "Functional expression and localization of P-glycoprotein in the central nervous system: relevance to the pathogenesis and treatment of neurological disorders," Pharmaceutical Research, vol. 21, no. 8, pp. 1313-1330, 2004.

[9] F. C. Lam, R. Liu, P. Lu et al., " $\beta$-amyloid efflux mediated by p-glycoprotein," Journal of Neurochemistry, vol. 76, no. 4, pp. 1121-1128, 2001.

[10] S. Vogelgesang, I. Cascorbi, E. Schroeder et al., "Deposition of Alzheimer's $\beta$-amyloid is inversely correlated with $\mathrm{P}$ glycoprotein expression in the brains of elderly non-demented humans," Pharmacogenetics, vol. 12, no. 7, pp. 535-541, 2002.

[11] S. Vogelgesang, R. W. Warzok, I. Cascorbi et al., "The role of P-glycoprotein in cerebral amyloid angiopathy; implications for the early pathogenesis of Alzheimer's disease," Current Alzheimer Research, vol. 1, no. 2, pp. 121-125, 2004.

[12] D. Kuhnke, G. Jedlitschky, M. Grube et al., "MDR1-Pglycoprotein (ABCB1) mediates transport of Alzheimer's amyloid- $\beta$ peptides - implications for the mechanisms of $A \beta$ clearance at the blood-brain barrier," Brain Pathology, vol. 17, no. 4, pp. 347-353, 2007.

[13] J. R. Cirrito, R. Deane, A. M. Fagan et al., "P-glycoprotein deficiency at the blood-brain barrier increases amyloid- $\beta$ deposition in an Alzheimer disease mouse model," Journal of Clinical Investigation, vol. 115, no. 11, pp. 3285-3290, 2005.

[14] A. M. S. Hartz, D. S. Miller, and B. Bauer, "Restoring blood-brain barrier P-glycoprotein reduces brain amyloid$\beta$ in a mouse model of Alzheimer's disease," Molecular Pharmacology, vol. 77, no. 5, pp. 715-723, 2010.

[15] R. Deane, Z. Wu, A. Sagare et al., "LRP/amyloid $\beta$-peptide interaction mediates differential brain efflux of $\mathrm{A} \beta$ isoforms," Neuron, vol. 43, no. 3, pp. 333-344, 2004.

[16] J. E. Donahue, S. L. Flaherty, C. E. Johanson et al., "RAGE, LRP-1, and amyloid-beta protein in Alzheimer's disease," Acta Neuropathologica, vol. 112, no. 4, pp. 405-415, 2006.
[17] B. V. Zlokovic, "New therapeutic targets in the neurovascular pathway in Alzheimer's disease," Neurotherapeutics, vol. 5, no. 3, pp. 409-414, 2008.

[18] G. D. Silverberg, A. A. Messier, M. C. Miller et al., "Amyloid efflux transporter expression at the blood-brain barrier declines in normal aging," Journal of Neuropathology \& Experimental Neurology, vol. 69, no. 10, pp. 1034-1043, 2010.

[19] K. Irie, K. Murakami, Y. Masuda et al., "Structure of $\beta$-amyloid fibrils and its relevance to their neurotoxicity: implications for the pathogenesis of Alzheimer's disease," Journal of Bioscience and Bioengineering, vol. 99, no. 5, pp. 437-447, 2005.

[20] M. D. Carte, G. A. Simms, and D. F. Weaver, "The development of new therapeutics for Alzheimer's disease," Clinical Pharmacology \& Therapeutics, vol. 88, no. 4, pp. 475-486, 2010.

[21] D. A. Butterfield, "Amyloid $\beta$-peptide [1-42]-assosiated free radical-induced oxidative stress and neurodegeneration in Alzheimer's disease brain: mechanisms and consequences," Current Medicinal Chemistry, vol. 10, no. 24, pp. 2651-2659, 2003.

[22] J. A. Nicolazzo and K. Katneni, "Drug transport across the blood-brain barrier and the impact of breast cancer resistance protein (ABCG2)," Current Topics in Medicinal Chemistry, vol. 9, no. 2, pp. 130-147, 2009.

[23] R. W. Robey, K. K. To, O. Polgar et al., "ABCG2: a perspective," Advanced Drug Delivery Reviews, vol. 61, no. 1, pp. 3-13, 2009.

[24] L. M. Tai, A. J. Loughlin, D. K. Male, and I. A. Romero, "P-glycoprotein and breast cancer resistance protein restrict apical-to-basolateral permeability of human brain endothelium to amyloid- $\beta$," Journal of Cerebral Blood Flow and Metabolism, vol. 29, no. 6, pp. 1079-1083, 2009.

[25] H. Xiong, D. Callaghan, A. Jones et al., "ABCG2 is upregulated in Alzheimer's brain with cerebral amyloid angiopathy and may act as a gatekeeper at the blood-brain barrier for $\mathrm{A} \beta(1-$ 40) peptides," Journal of Neuroscience, vol. 29, no. 17, pp. 5463-5475, 2009.

[26] B. Tan, D. Piwnica-Worms, and L. Ratner, "Multidrug resistance transporters and modulation," Current Opinion in Oncology, vol. 12, no. 5, pp. 450-458, 2000.

[27] A. Asghar, J. C. Gorski, B. Haehner-Daniels, and S. D. Hall, "Induction of multidrug resistance-1 and cytochrome P450 mRNAS in human mononuclear cells by rifampin," Drug Metabolism and Disposition, vol. 30, no. 1, pp. 20-26, 2002.

[28] G. Jedlitschky, S. Vogelgesang, H. K. Kroemer et al., "MDR1P-glycoprotein (ABCB1)-mediated disposition of amyloid- $\beta$ peptides: implications for the pathogenesis and therapy of Alzheimer's disease," Clinical Pharmacology \& Therapeutics, vol. 88, no. 4, pp. 441-443, 2010. 


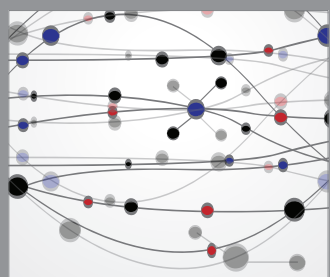

The Scientific World Journal




Gastroenterology

Research and Practice
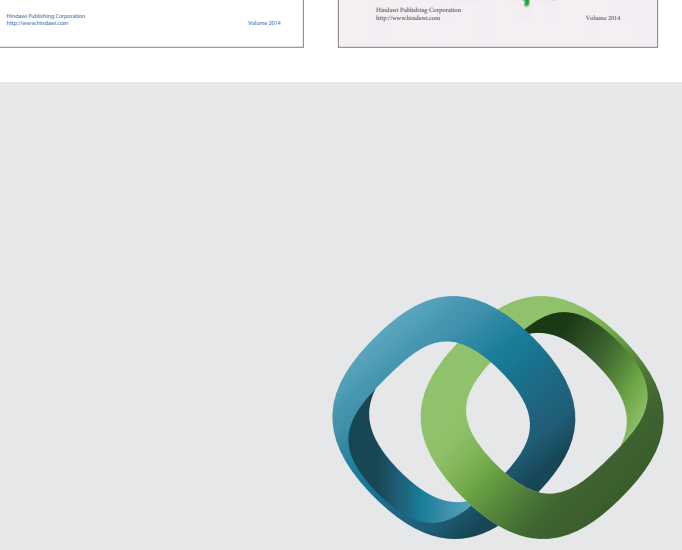

\section{Hindawi}

Submit your manuscripts at

http://www.hindawi.com
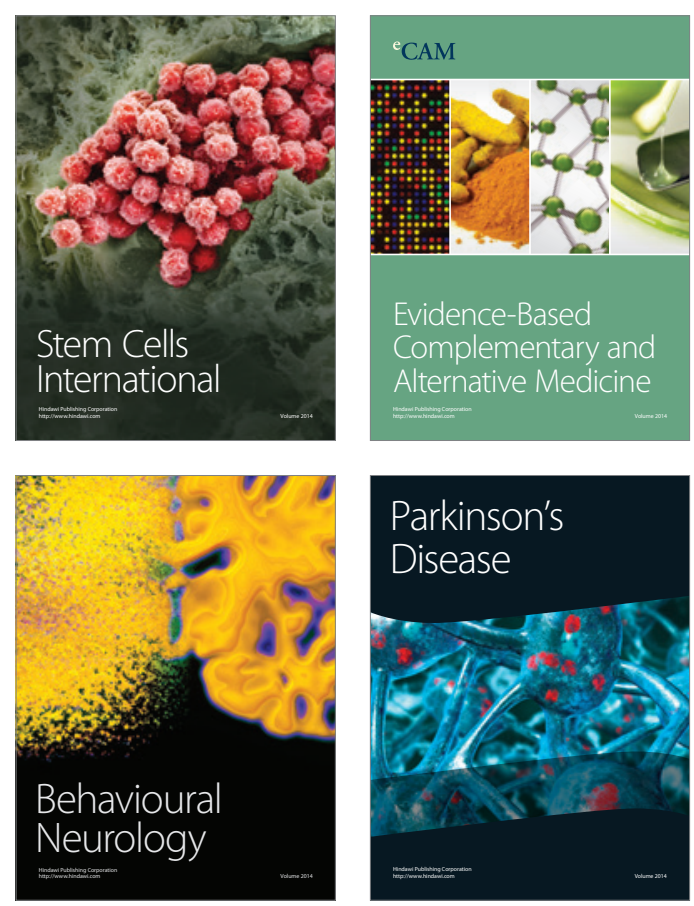



Journal of
Diabetes Research

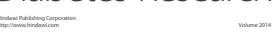

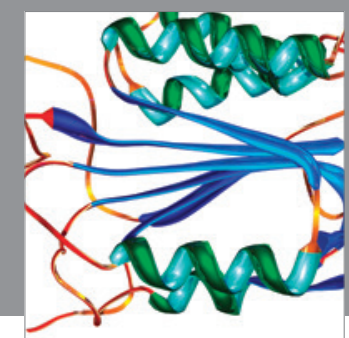

Disease Markers
